\title{
Appetite suppression caused by CCK is diet specific in VMH-lesioned rats
}

\author{
RICHARD KRINSKY, ELIZABETH C. LOTTER, and STEPHEN C. WOODS \\ University of Washington, Seattle, Washington 98195
}

\begin{abstract}
Intraperitoneal injections of the C-terminal octapeptide of cholecystokinin-pancreozymin (CCK) failed to inhibit 5.5-h-fasted feeding of a high-fat diet in rats with electrolytic lesions of the ventromedial hypothalamus. Similar injections significantly reduced the intake of a high-fat diet in sham-lesioned controls. These results are consistent with Powley's (1977) cephalic phase hypothesis $(\mathrm{CPH})$ and are interpreted to mean that rats with electrolytic lesions of the ventromedial hypothalamus, when given a highly palatable diet, demonstrate a prolonged cephalic reflex, which results in metabolic disturbances which may override the effect of CCK at the $40 \mathrm{U} / \mathrm{kg}$ dose.
\end{abstract}

Previous studies in our laboratory have demonstrated that injections of the C-terminal octapeptide of cholecystokinin-pancreozymin (CCK) elicited a decrease of feeding in 5.5-h-fasted rats with bilateral electrolytic lesions of the ventromedial hypothalamic (VMH) nucleus (Kulkosky, Breckenridge, Krinsky, $\&$ Woods, 1976). Similar results have been obtained with normal adult rats (Gibbs, Young, \& Smith, 1972, 1973), weanling rats (Bernstein, Lotter, \& Zimmerman, 1976), mice (Koopmans, Deutsch, \& Branson, 1972), and rhesus monkeys (Gibbs, Falasco, \& McHugh, 1976).

In our previous experiment on VMH-lesioned rats (Kulkosky et al., 1976), Purina Rat Chow, which is generally considered to be only of moderate palatability, was the diet. Palatibility of the diet is an important variable, since rats with damage to the VMH are "finicky eaters," consuming large amounts of a highly palatable diet while eating less than controls on diets that are unpalatable (Corbit \& Stellar, 1964; Panksepp, 1971; Teitelbaum, 1955). We therefore extended our previous investigation by investigating whether or not CCK would be effective as an appetite suppressant for VMH-lesioned rats consuming a more palatable diet.

\section{METHOD}

The subjects were 18 experimentally naive male Wistar rats obtained from the colony maintained by the University of Washington Department of Psychology. The animals were between 120 and 180 days of age and weighed an average of $480 \mathrm{~g}$. They were housed in standard individual stainless steel cages and had ad-lib access to Purina Rat Chow pellets and water, unless otherwise specified. They were maintained on a 12:12 light-dark schedule (on at 8:00 a.m.).

The rats were anesthetized with Equithesin $(3 \mathrm{ml} / \mathrm{kg})$ following $0.15 \mathrm{ml}$ atropine sulfate. The rats were placed in a stereotaxic

This research was supported by NIH Grant AM 17844. apparatus, and bilateral electrolytic lesions were made by passing $2 \mathrm{~mA}$ of direct anodal current for $15 \mathrm{sec}$ between a stainless steel electrode, insulated except for $0.4 \mathrm{~mm}$ at the tip, and a cathode connected to an ear bar, with the electrode aimed at the following coordinates (Pellegrino \& Cushman, 1967): AP $+5.8 \mathrm{~mm}$, $\mathrm{L} \pm 0.75 \mathrm{~mm}, \mathrm{DV}-3.25 \mathrm{~mm}$. Bilateral electrolytic lesions were made in nine randomly selected rats. All other rats were anesthesized with Equithesin and placed in a stereotaxic apparatus. Then a stainless steel electrode was inserted, bilaterally, into the VMH nucleus. The current was not turned on during this procedure. The subjects were allowed 2 weeks to recover before initiation of testing.

Each rat was habituated for 2 weeks to a daily fooddeprivation schedule from 10:00 a.m. to 3:30 p.m. At 3:30 p.m., each rat received an intraperitoneal injection of isotonic $(0.9 \%)$ saline $(1 \mathrm{ml} / \mathrm{kg})$ and was given food. Intakes of a diet of ground Purina Rat Chow and Crisco shortening in equal proportions were measured $30 \mathrm{~min}$ after presentation (i.e., 4:00 p.m.). A rat had to consume an average of at least $1 \mathrm{~g}$ of food during the $30 \mathrm{~min}$ to be continued in the experiment. After this 2-week habituation procedure, a test of the effectiveness of CCK was made. On the 15th day of the experiment, injections of the octapeptide of CCK, at the $40-\mathrm{U} / \mathrm{kg}$ dose, were given in the place of saline. We have demonstrated that this dose of CCK is maximally effective in reducing food intake (Kulkosky et al., 1976). At the conclusion of the experiment, each rat was sacrificed with an overdose of chloroform and perfused intracardially with isotonic saline followed by Formalin. Forty- $\mu$ sections of the hypothalamus were subsequently prepared and examined.

\section{RESULTS}

Food intake in one experimental rat and six shamlesioned controls was consistently less than $1 \mathrm{~g}$ per day during habituation. These rats were discarded from the study prior to testing with CCK, and their data have been omitted from this report.

The data for the VMH-lesioned rats are summarized in Figure 1.

Injections of CCK did not decrease food intake below that of the previous day on which saline was injected $[t(7)=-.19, p>.10]$. Injections of CCK, however, significantly decreased food intake in the remaining sham-lesioned controls. When the propor- 


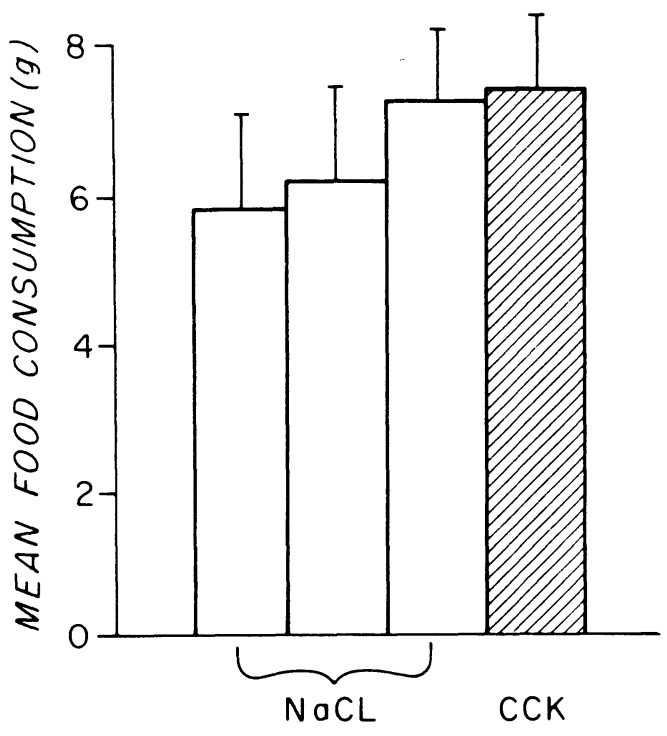

Figure 1. Mean food intake (in grams) of rats with lesions of the ventromedial hypothalamus in the $30 \mathrm{~min}$ after injection with either saline or $40 \mathrm{U} / \mathrm{kg}$ of $\mathrm{CCK}$. Lines above the means represent one standard error of the mean.

tional decrease of food consumption below that of the previous day on which saline was injected was considered as our dependent measure, results of the Mann-Whitney $U$ test indicated that the ordered food intake of the sham-lesioned controls was significantly less than that of the VMH-lesioned rats $(p<.05)$. However, when food consumption on the day prior to testing with CCK was considered as our dependent measure, results of the Mann-Whitney $\mathrm{U}$ test indicated that during the first $.5 \mathrm{~h}$ following injection of saline, there was no ordered difference in food intake between the two groups $(p>.05)$. These data are presented in Figure 2.

Verification of the VMH lesions was obtained using a single-blind technique. Results indicated there were large bilateral lesions in the VMH-lesioned group and that all rats were categorized into their respective groups via histological examination. The lesions were similar to those described in our previous report (Kulkosky et al., 1976).

\section{DISCUSSION}

Given dry Purina Rat Chow, rats with VMH lesions decreased feeding following injection of the octapeptide of CCK (Kulkosky et al., 1976). This finding suggests that integrity of the $\mathrm{VMH}$ is not essential for the production of satiety following injection of CCK. We now report that rats with similar VMH lesions, tested with a palatable high-fat diet, did not respond to intraperitoneal injections of the octapeptide of CCK by reducing their food intake, Since sham lesioned controls, when offered this highfat diet responded to CCK with a reduction of food intake, we concluded that our obtained results of the VMH-lesioned rats was not an artifact resulting from any change in the potency of the CCK.

The response of VMH-lesioned rats to satiety elicited by the octapeptide of CCK is consistent with previously reported findings which describe animals with VMH lesions as "finicky" (i.e., overeating being dependent on the sensory qualities of the foodstuff). In a recent review of the ventromedial hypothalamic syndrome, Powley (1977) postulated that finickiness following damage to the $\mathrm{VMH}$ is a function of the exaggeration of the efferent limb of the cephalic reflexes of digestion, which, in turn, alter the amplitude (either positive or negative) of the cephalic responses to sensory aspects of food. It has been demonstrated that various sensory dimensions affect the degree of hyperphagic weight gain in VMH-lesioned rats. Studies with nonnutritive greasy additives suggest that VMH-lesioned animals overrespond to the taste and textural aspects of the highfat diet rather than to its postingestional effects (Corbit \& Stellar, 1964; Strubbe \& Steffens, 1975).

Our results support the cephalic phase hypothesis $(\mathrm{CPH})$ as forwarded by Powley. It is our conclusion that metabolic adjustments which produce overeating in the VMH-lesioned animal are a result of an exaggerated cephalic response triggered by the sensory aspects of the more palatable food and that this exaggerated response is sufficient to override the effectiveness of CCK at the $40-\mathrm{U} / \mathrm{kg}$ dose.

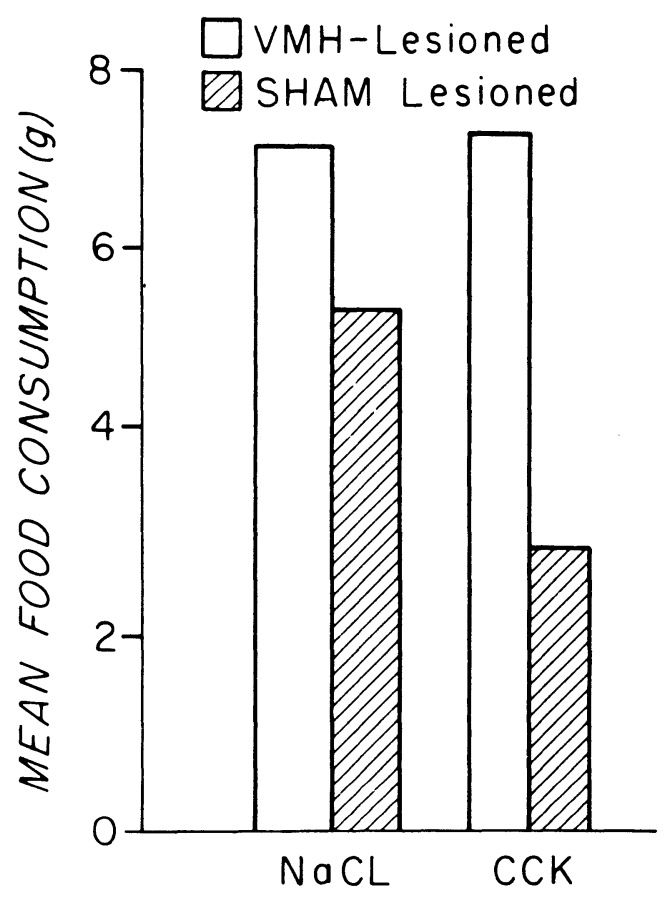

Figure 2. Mean food intake (in grams) of rats with lesions of the ventromedial hypothalamus and sham-lesioned controls. Measurements were made $\mathbf{3 0}$ min after injection with either saline or $40 \mathrm{U} / \mathrm{kg} \mathrm{CCK}$. 


\section{REFERENCES}

Bernstein, I. L., Lotter, E. C., \& Zimmerman, J. C. Cholecystokinin-induced satiety in weanling rats. Physiology \& Behavior, 1976, 17, 541-543.

Corbit, J. D., \& Stellar, E. Palatability, food intake, and obesity in normal and hyperphagic rats. Journal of Comparative and Physiological Psychology, 1964, 58, 63-67.

Gibbs, J., Falasco, J., \& McHugh, P. R. Cholecystokinin-decreased food intake in rhesus monkeys. American Journal of Psychology, 1976, 230, 15-18.

Gibis, J., Young, R. C., \& Smith, G. P. Effect of gut hormones on feeding behavior in the rat. Federation Proceedings, 1972, 31, 397.

Gibis, J., Young, R. C., \& Smith, G. P. Cholecystokinin decreases food intake in rats. Journal of Comparative and Physiological Psychology, 1973, 84, 488-495.

Koopmans, H. S., Deutsch, J. A., \& Branson, P. J. The effect of cholecystokinin-pancreozymin on the hunger and thirst in mice. Behavioral Biology, 1972, 7, 441-444.
Kulkosky, P. J., Breckenridge, C., Krinsky, R., \& Woods, S. C. Satiety elicited by the C-terminal octapeptide of cholecystokinin-pancreozymin in normal and VMH-lesioned rats. Behavioral Biology, 1976, 18, 227-234.

PANKSEPP, J. Is satiety mediated by the ventromedial hypothalamus? Physiology \& Behavior, 1971, 6, 311-316.

Pellegrino, L. J., \& Cushman, A. J. A stereotaxic atlas of the rat brain. New York: Appleton-Century-Crofts, 1967.

Powley, T. L. The ventromedial hypothalamic syndrome, satiety, and a cephalic phase hypothesis. Psychological Review, 1977, 84, 89-126.

Strubbe, J. H., \& Steffens, A. B. Rapid insulin release after injestion of a mean in the unanesthesized rat. American Journal of Physiology, 1975, 229, 1019-1022.

Teitlebaum, P. Sensory control of hypothalamic hyperphagia. Journal of Comparative and Physiological Psychology, 1955, 48, 156-163.

(Received for publication January 31, 1978; revision accepted May 2, 1978.) 